\title{
Simplified Lumped Parameter Thermal Network for Short-Duty Dual Three-Phase Permanent Magnet Machines
}

\author{
P. Giangrande ${ }^{1}$, V. Madonna ${ }^{1}$, W. Zhao ${ }^{2}$, Y. Wang ${ }^{2}$, C. Gerada ${ }^{1}$, Michael Galea ${ }^{1,2}$ \\ ${ }^{1}$ Power Electronics, Machines and Control Group, University of Nottingham, Nottingham, UK \\ ${ }^{2}$ School of Aerospace, University of Nottingham Ningbo, China \\ p.giangrande@nottingham.ac.uk
}

\begin{abstract}
Electrical machines are progressively being employed in an ever-increasing number of safety-critical applications (e.g. aerospace and automotive), which demand high performance as well as reliability features. The modular structure and the inherent winding redundancy of dual three-phase machines are noticeable attributes that make these fault-tolerant machines particularly suitable for safety-critical applications. However, conventional thermal networks might produce misleading results, when applied to dual three-phase machines. Indeed, they generally neglect the thermal mutual coupling between windings belonging to different phase sets, since only a single slot is modelled. This paper addresses the aforementioned issue by presenting two lumped parameters thermal networks (second- and third-order), which account for the thermal behavior of both winding sets. The proposed thermal networks are experimentally validated and between them, the third-order one is chosen as best candidate for predicting the windings' temperature, due to its simplicity, accuracy and fast computational time.
\end{abstract}

Index Terms - Electrical Machines Design, Lumped Parameters Thermal Network, Thermal Modeling, Dual Three-Phase, Fault-Tolerant, Permanent Magnet Synchronous Machine

\section{INTRODUCTION}

Systems where a failure or a malfunction might endanger human life or cause extensive economic loss are identified as safety-critical [1]. Hence, electrical machines employed in safety-critical systems must present the ability to operate even during/after severe faults. In the last two decades, several topologies of fault-tolerant machines have been proposed and developed to comply with the reliability and availability requirements typical of safety-critical applications [2-4]. In general, permanent magnet synchronous machines (PMSMs) equipped with multiphase windings are often selected to simultaneously meet the performance constraints [5-7] and ensure the operation continuity under fault conditions [8-11]. Among multiphase PMSMs, those featuring two separate three-phase windings wound on the same stator core, i.e. dual three-phase winding PMSMs, represent a viable solution for safety-critical applications (e.g. aerospace and automotive).

This work was funded by the INNOVATIVE doctoral programme. The INNOVATIVE programme is partially funded by the Marie Curie Initia Training Networks (ITN) action (project number 665468) and partially by the Institute for Aerospace Technology (IAT) at the University of Nottingham.

This work has also received funding from the Clean Sky 2 Joint Undertaking under the European Union's Horizon 2020 research and innovation programme under grant agreement No 807081.
In fact, they reveal a good compromise between fault-tolerance capability and the adoption of standard power electronic converters (PECs) [12-13].

Similarly to the conventional three-phase machines, the thermal analysis and consequently the thermal management are at the core of a comprehensive multiphysics design of dual three-phase PMSMs [14-16]. Different modeling techniques, such as computational fluid dynamics (CFDs), finite-element (FE) methods and lumped parameters thermal networks (LPTNs), are available for investigating and evaluating the thermal behavior of electrical machines [17, 18]. The LPTNs are a common choice for electrical machine designers, since they are characterized by relatively uncomplicated implementation and they can provide fast and accurate temperature prediction if experimentally fine-tuned. For steady-state temperature estimation, which is usual in continuous service electrical machines, the LPTN tuning procedure only requires the calculation of thermal resistances (i.e. thermal capacitances are omitted from the LPTN). Nevertheless, there are short-duty applications, where the electrical machine is not expected to reach the steady-state temperature $[14,19-21]$; thus, the transient temperature estimation is needed. Electromechanical actuators (EMAs) for aerospace are a classical example of short-duty application, because their mission profile (i.e. operating time) normally lasts just few minutes [9, 22]. Therefore, a reduced-order LPTN can be used for modelling the thermal behavior of an electrical machine embedded in an EMA.

In literature, a number of reduced-order LPTNs have been presented and deeply investigated [23]. Nonetheless, the majority of these models refer to conventional three-phase machines, hence, the thermal mutual coupling between windings belonging to different phase sets is not accounted [24]. In dual three-phase PMSM, the thermal coupling plays an important role, since a failure in one winding set, which is source of over-temperature, should not compromise the correct functioning of the healthy winding set [25]. Thus, it is clear that conventional LPTNs (either high- or low-order) are not suitable for evaluating the thermal mutual coupling between winding sets, as they model a single slot or assume the same current magnitude (i.e. uniform Joule losses distribution) in each winding section [26].

Considering the above premises, two reduced-order LPTNs (second- and third-order), which are capable of modeling the thermal interaction between the winding sets of the dual three-phase PMSM (i.e. the LPTNs consist of two slots each), are introduced in this paper. The LPTNs' fine-tuning procedure is given and the effectiveness of the third-order 
LPTN is experimentally proved. Finally, the potential applications of the proposed third-order LPTN are briefly discussed.

\section{CASE-Study: DuAl Three-PHASE PMSM DESCRIPTION}

With the aim of providing a case-study for the thermal investigation, a dual three-phase PMSM, which has been designed by the authors, is considered. The electrical machine has been developed for an aerospace EMA application (i.e. short-duty application) and its geometry and winding layout are shown in Fig. 1, while the main parameters are listed in TABLE I.

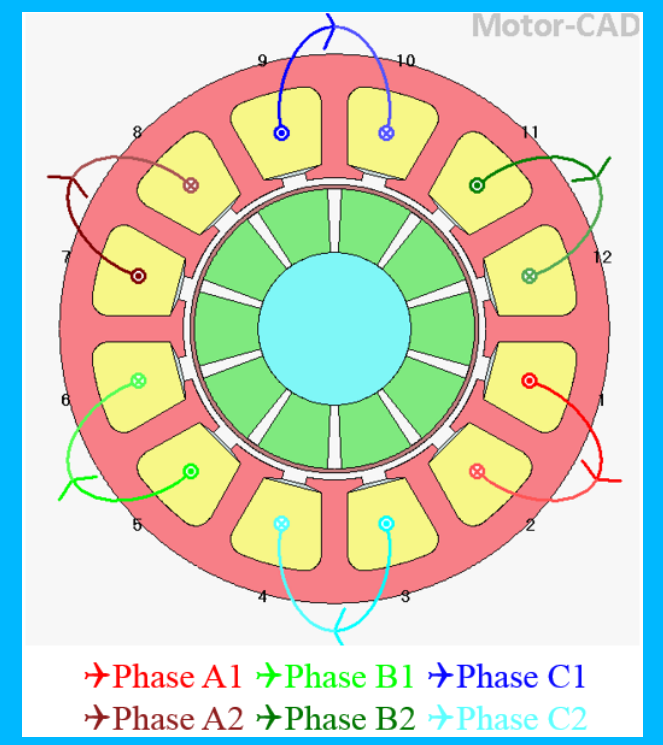

Fig. 1: Geometry and winding layout of the dual three-phase PMSM at hand.

As outcome of a trade-off analysis, a 12 slots / 10 poles configuration has been selected to meet the application specifications, whilst a single layer concentrated winding has been chosen to comply with fault-tolerance requirements. In fact, the phase-to-phase short-circuit risk is mitigated, being the coils galvanically-isolated (i.e. non-overlapping) [27]. In addition, the short-circuit currents are limited by the high per-phase self-inductance, whereas the electromagnetic mutual coupling between the two winding sets is negligible (i.e. mutual inductance approaching zero) [28, 29].

TABLE I DUAL THREE-PHASE PMSM PARAMETERS

\begin{tabular}{|l|l|l|}
\hline \hline Parameter & Symbol & Value \\
\hline Rated Speed $[\mathrm{rpm}]$ & $\Omega_{\mathrm{PMSM}}$ & 2500 \\
\hline Rated Torque $[\mathrm{Nm}]$ & $\tau_{\mathrm{PMSM}}$ & 1 \\
\hline Rated Current $\left[\mathrm{A}_{\mathrm{rms}}\right]$ & $\mathrm{I}_{\mathrm{n}}$ & 1.1 \\
\hline Phase Resistance $[\Omega]$ & $\mathrm{R}$ & 3.24 \\
\hline d-axis Inductance $[\mathrm{mH}]$ & $\mathrm{Ld}_{\mathrm{H}}$ & 13.7 \\
\hline q-axis Inductance $[\mathrm{mH}]$ & $\mathrm{Lq}_{\mathrm{q}}$ & 13.7 \\
\hline PM Flux [Wb] & $\Psi_{\mathrm{PM}}$ & 0.112 \\
\hline Stack Length $[\mathrm{mm}]$ & $\mathrm{L}$ & 50 \\
\hline Stator Outer Diameter $[\mathrm{mm}]$ & $\mathrm{D}_{\mathrm{o}}$ & 50 \\
\hline \hline
\end{tabular}

The two winding sets (i.e. set ' 1 ' and set ' 2 ') are star-connected and both neutral points are insulated [30]. The phase shift angle between the winding sets (i.e. angle between phase ' $\mathrm{A} 1$ ' and phase 'A2' axes) is equal to zero degrees, as can be noted in Fig. 1. Each winding set is connected to an independent PEC and the following operating modes are allowed [31-32]:

1) the active-active mode, where both winding sets are fed with half of the rated current (i.e. healthy condition);

2) the active-open mode, when only one winding set is supplied at rated current, whilst the other is open (i.e. fault occurring on the PEC);

3) the active-shorted mode, which consists in one winding set powered, whereas the other is short-circuited (i.e. fault arising in one PMSM winding set).

In terms of thermal management, the dual three-phase PMSM at hand relies on a natural air cooling system enhanced by the adoption of a finned aluminum housing. The cooling system's choice is justified by the fact that a) the machine is not expected to reach steady-state temperature at any point in time and b) complex cooling infrastructure (e.g. liquid cooling) are generally avoided in aerospace EMA, due to weight and reliability limitations [33-34].

\section{SECOND-ORDER LPTN For DUAL THREE-PHASE PMSM}

In general, the LPTN's computational time is related to the number of thermal capacitances implemented (i.e. LPTN order). Hence, fewer reactive components will result in a faster temperature prediction. However, it is worthy to point out that the LPTN quickness comes at the cost of lower accuracy in terms of temperature distribution within the electrical machine. In order to build a fast tool for analyzing the thermal behavior of the dual three-phase PMSM, which includes the thermal mutual coupling, the 3-nodes second-order LPTN reported in Fig. 2 has been initially considered.

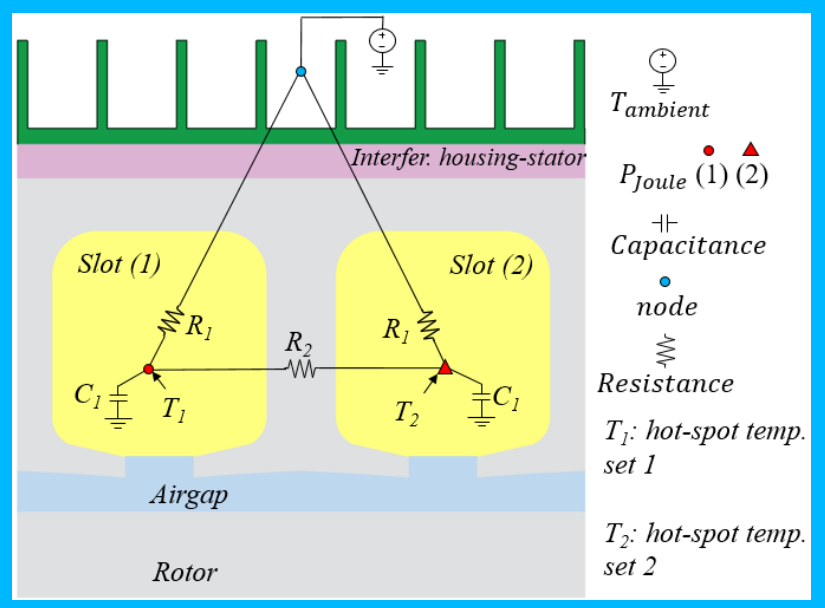

Fig. 2: Second-order LPTN modeling two slots of the dual three-phase PMSM.

As depicted in Fig. 2, one thermal node is used for modelling the ambient temperature and a voltage source is connected to it, while the remaining two nodes are placed within as many slots, each belonging to a different winding set. Two heat sources are respectively connected to the latter thermal nodes and they account for the Joule losses in every winding set giving the opportunity to of predict the winding 
hot-spot temperature under asymmetric load conditions. Further, this feature allows to quantify the thermal mutual influence between winding sets, which is extremely useful for verifying the dual three-phase PMSM's compliance to the fault-tolerant requirements. Indeed, an over-temperature (e.g. caused by an inter-turn short-circuit) in one winding set should not lead to a significant temperature rise in the adjacent slot, where the conductors belonging to the healthy winding set are situated.

The second-order LPTN consists of 3 thermal resistances and 2 thermal capacitances (the order of a LPTN corresponds to the number of thermal capacitances). The heat transfer from each slot to the external ambient is modelled by the two resistances marked as ' $R_{1}$ ', which represent the equivalent 'heat barrier' between the winding hot-spot and the external ambient air. The thermal resistance ' $\mathrm{R}_{2}$ ' models the mutual coupling between the two slots belonging to different winding sets. Therefore, its value includes the homogenized slot resistance in the tangential (i.e. circumferential) direction, the slot liner and the iron tooth. Exploiting the PMSM geometrical symmetry, two thermal capacitances identified as ' $\mathrm{C}_{1}$ ' are respectively located in every slot.

The presented LPTN has been developed assuming that the hot-spot temperature-rise is solely caused by the winding losses due to the Joule effect. Such assumption is supported by the small amount of iron losses produced within the PMSM, which are more than one order of magnitude lower than Joule losses according to the FE electromagnetic simulations. Thus, the iron losses only give a non-negligible temperature-rise contribution at steady-state, which is not the case of the application under study. For this reason, DC currents have been adopted for fine-tuning and validating the second-order LPTN, as discussed in the next section.

\section{A. Second-Order LPTN Fine-Tuning and Validation}

After defining the architecture of the LPTN, the experimental fine-tuning procedure is performed with the purpose of accurately determining the numerical value of the LPTN's components (i.e. thermal resistances and capacitance). During the experimental tests, two coils allocated in adjacent slots and belonging to different three-phase sets are fed through separate DC power sources, as illustrated in Fig. 3.

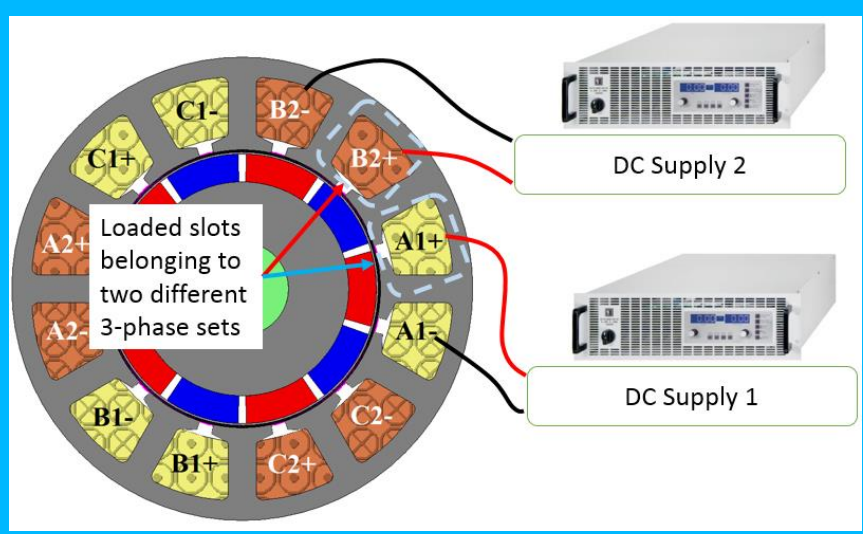

Fig. 3: Layout of the DC power supplies employed during the thermal tests.

The winding temperatures are acquired via K-Type thermocouples uniformly distributed in the PMSM's windings and they are recorded using a temperature data logger. For sake of completeness, the overview of the whole experimental setup is shown in Fig. 4. Throughout the test campaign, a large number of acquisitions has been carried out considering both symmetric (i.e. $\mathrm{I}_{1}=\mathrm{I}_{2}$ ) and asymmetric (i.e. $I_{1} \neq I_{2}$ ) load conditions with several current amplitudes. Part of the collected data have been used for identifying the LPTN's components, whereas the remaining data have been kept for validation purpose.

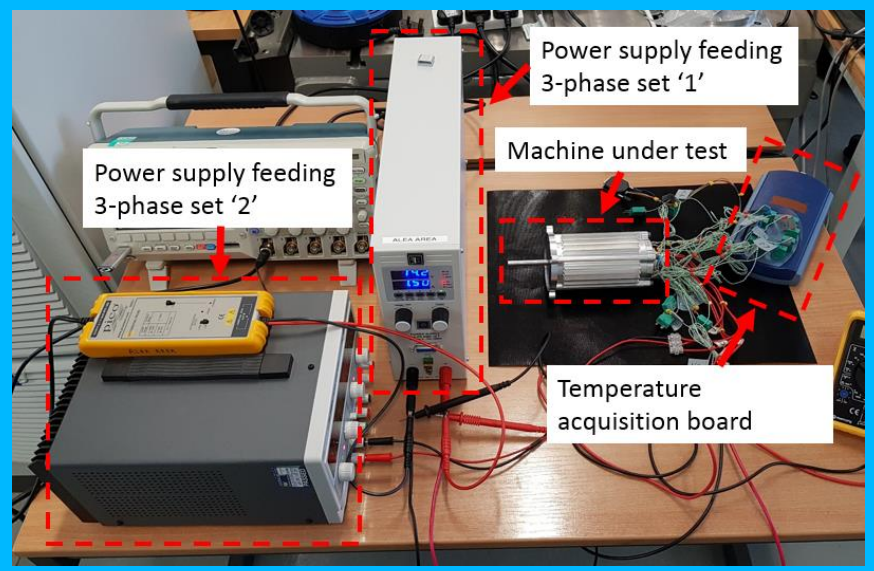

Fig. 4: Complete experimental setup for the thermal tests.

The first set of acquired temperatures have been imported in the Simulink ${ }^{\circledR}$ Design Optimization Toolbox, which allows to identify the thermal resistances and capacitances by means of a sequential quadratic programming (SQP) algorithm. The resulting fine-tuned parameters of the second-order LPTN are listed in TABLE II.

TABLE II SECOND-ORDER LPTN FINE-TUNED PARAMETERS

\begin{tabular}{|c|c|c|}
\hline \hline Parameter & Magnitude & Unit \\
\hline $\mathrm{R}_{1}$ & 9.94 & $\mathrm{~K} / \mathrm{W}$ \\
\hline $\mathrm{R}_{2}$ & 13.79 & $\mathrm{~K} / \mathrm{W}$ \\
\hline $\mathrm{C}_{1}$ & 16.15 & $\mathrm{~J} / \mathrm{K}$ \\
\hline
\end{tabular}

Once the LPTN's parameters have been estimated, the fine-tuned thermal tool has been employed for predicting the winding hot-spot temperature. Regarding the symmetric load conditions (i.e. $I_{1}=I_{2}$ ), the comparison between experimental and second-order LPTN-predicted temperature profiles is reported in Fig. 5, where only the hot-spot temperature in one slot (i.e. ' $T_{1}$ ') is shown for the sake of figure clarity.

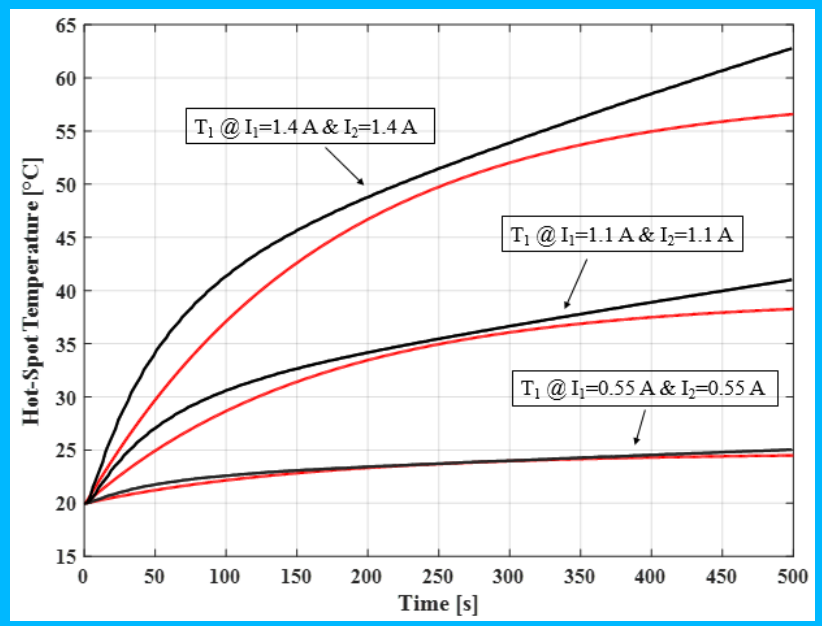

Fig. 5: Hot-spot temperature in symmetric load conditions: experimental (black) and second-order LPTN-predicted (red) profiles. 
For the same reason, only the temperature profiles corresponding to the current magnitude of $0.55,1.1$ and $1.4 \mathrm{~A}$ are considered in Fig. 5. Similarly, the outcomes of the asymmetric load conditions (i.e. $\mathrm{I}_{1} \neq \mathrm{I}_{2}$ ) are summarized in Fig. 6, where the second-order LPTN-predicted and measured hot-spot temperature profiles are reported for $\mathrm{I}_{1}=1.5 \mathrm{~A}$ and $\mathrm{I}_{2}=1.1 \mathrm{~A}$.

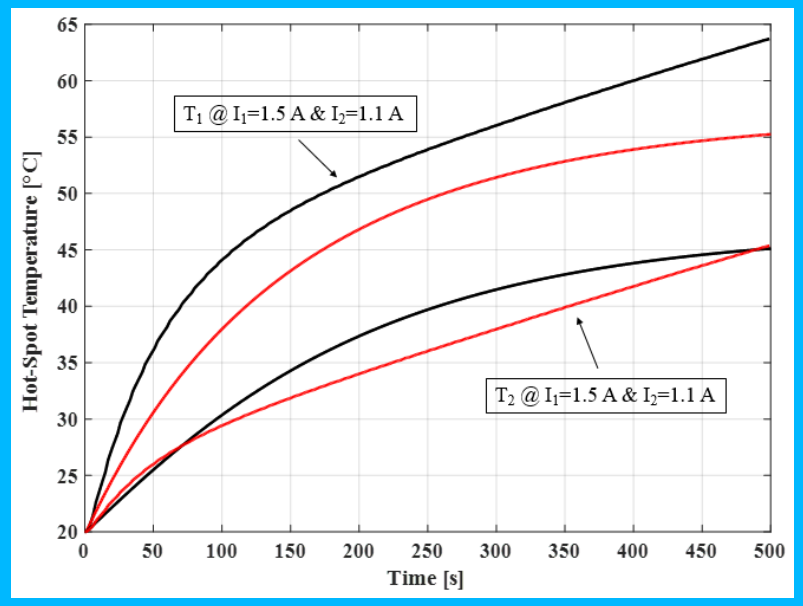

Fig. 6: Hot-spot temperature in asymmetric load conditions: experimental (black) and second-order LPTN-predicted (red) profiles.

Analyzing the results obtained using the 3-nodes second-order LPTN, a non-negligible mismatch between actual and estimated temperatures is highlighted in both the examined cases (i.e. symmetric and asymmetric load conditions). This mismatch has been analytically quantified through the integral absolute error (IAE), which is defined as the time integral of the absolute error $|\varepsilon|$ between measured and estimated temperatures. According to its definition, the IAE can be expressed as in (1), where the upper limit of the acquisition time-window is equal to $500 \mathrm{~s}$ (i.e. maximum operating time of the EMA case-study). For every tested load combination, the IAE values have been determined and they are listed in TABLE III.

$$
I A E=\int_{0}^{500 s}|\varepsilon| d t
$$

TABLE IIIII IAE VALUES OF THE SECOND-ORDER LPTN FOR SEVERAL CURRENT COMBINATIONS

\begin{tabular}{|c|c|c|c|}
\hline \hline $\begin{array}{c}\mathbf{I}_{\mathbf{1}} \\
{[\mathbf{A}]}\end{array}$ & $\begin{array}{c}\mathbf{I}_{\mathbf{2}} \\
{[\mathbf{A}]}\end{array}$ & $\begin{array}{c}\mathbf{T}_{\mathbf{1}} \mathbf{I A E} \\
\left(\mathbf{2}^{\text {nd }} \mathbf{O r d e r} \mathbf{L P T N}\right) \\
{\left[{ }^{\circ} \mathbf{C ~ s}\right]}\end{array}$ & $\begin{array}{c}\mathbf{T}_{\mathbf{2}} \mathbf{I A E} \\
\left(\mathbf{2}^{\text {nd }} \mathbf{O r d e r} \mathbf{L P T N}\right) \\
{\left[{ }^{\circ} \mathbf{C ~} \mathbf{~}\right]}\end{array}$ \\
\hline 0.55 & 0.55 & 117.60 & 160.02 \\
\hline 1.1 & 0.55 & 1011.60 & 542.77 \\
\hline 1.1 & 1.1 & 490.77 & 409.19 \\
\hline 1.5 & 0.55 & 2791.70 & 1216.10 \\
\hline 1.5 & 1.1 & 2660.80 & 1029.00 \\
\hline 1.4 & 1.4 & 1550.80 & 871.99 \\
\hline 1.5 & 1.5 & 1848.00 & 1042.40 \\
\hline
\end{tabular}

Looking at TABLE III, it is evident that the IAE increases for higher current values, which might be a consequence of the time constants discrepancy (i.e. the 3-nodes second-order LPTN is slower than the actual plant) that significantly affects the prediction error. For achieving an improved temperature prediction, the preliminary 3-nodes second-order LPTN (see Fig. 2) requires some modifications, as addressed in the upcoming section.

\section{THIRD-ORDER LPTN FOR DUAL THREE-PHASE PMSM}

The poor estimation performance featured by the 3-nodes second-order LPTN can be ascribed to its very simple architecture that led to a fast but not very accurate thermal analysis tool. For this reason, the LPTN complexity should be slightly increased for finding a better trade-off between temperature prediction quality and computational burden. Starting from the configuration depicted in Fig. 2 and based on the outcomes presented in the previous section, the LPTN has been upgraded by adding a thermal capacitance ' $\mathrm{C}_{2}$ ' along with an additional thermal node. Thus, a 4-nodes third-order LPTN has been considered for describing the thermal behavior of the dual three-phase PMSM. A trade-off study has been performed for determining the optimal location of the additional capacitance ' $\mathrm{C}_{2}$ ' and its node. Relying on this analysis, the capacitance ' $\mathrm{C}_{2}$ ' has been placed in-between the two slots and the resistance ' $\mathrm{R}_{2}$ ' (which accounts for the mutual coupling between adjacent slots) has been split in two (i.e. $\mathrm{R}_{2} / 2$ ), as shown in Fig. 7, where the 4-nodes third-order LPTN is illustrated.

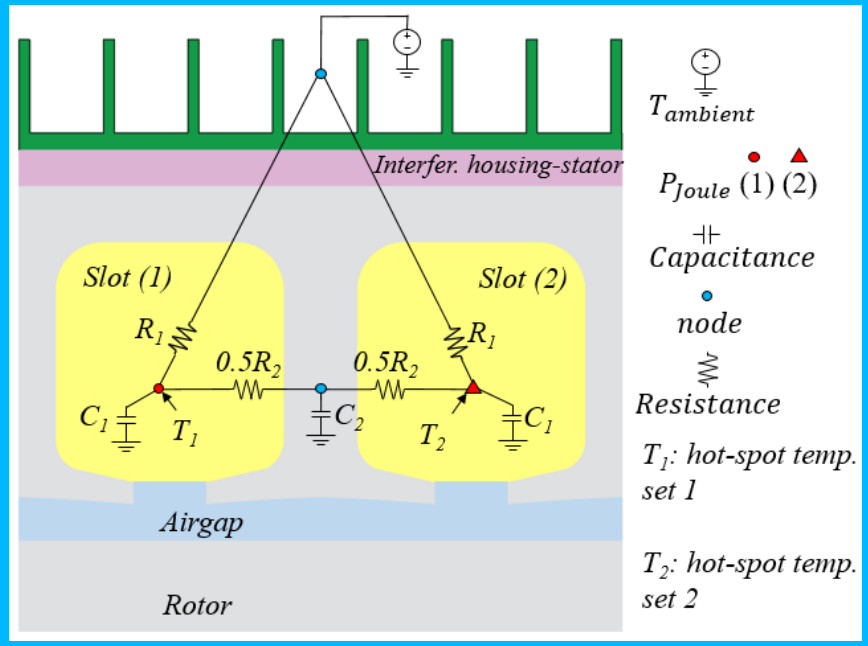

Fig. 7: Third-order LPTN modeling two slots of the dual three-phase PMSM.

Chosen the layout of the new LPTN, the numerical values of its components (i.e. ' $\mathrm{R}_{1}$ ', ' $\mathrm{R}_{2}$ ', ' $\mathrm{C}_{1}$ ' and ' $\mathrm{C}_{2}$ ') have been identified using the temperature profile previously recorded and following the fine-tuning procedure introduced in Section III. Therefore, the 4-nodes third-order LPTN's parameters resulting from Simulink ${ }^{\circledR}$ Design Optimization Toolbox are listed in TABLE IV.

TABLE IV THIRD-ORDER LPTN FINE-TUNED PARAMETERS

\begin{tabular}{|c|c|c|}
\hline \hline Parameter & Magnitude & Unit \\
\hline $\mathrm{R}_{1}$ & 64.7 & $\mathrm{~K} / \mathrm{W}$ \\
\hline $\mathrm{R}_{2}$ & 3.46 & $\mathrm{~K} / \mathrm{W}$ \\
\hline $\mathrm{C}_{1}$ & 10.35 & $\mathrm{~J} / \mathrm{K}$ \\
\hline $\mathrm{C}_{2}$ & 119.6 & $\mathrm{~J} / \mathrm{K}$ \\
\hline
\end{tabular}

The updated LPTN has been validated against the same experimental temperature profiles employed during the validation of the second-order LPTN. The comparisons between measured and third-order LPTN-predicted winding hot-spot temperatures, for both symmetric (i.e. $\mathrm{I}_{1}=\mathrm{I}_{2}$ ) and asymmetric (i.e. $I_{1} \neq I_{2}$ ) load conditions, are shown in Fig. 8 and Fig. 9 respectively. From these figures, it is clear that the third-order LPTN features better temperature prediction 
performance compared to the second-order one. Hence, the extra thermal capacitance ' $\mathrm{C}_{2}$ ' brings a remarkable reduction of the IAE, as proved by TABLE V's results. Indeed, the IAE percent variation (i.e. $\triangle \mathrm{IAE} \%$ ) between the second- and third-order LPTNs has been calculated according to (2) for different current combinations and the obtained values are summarized in TABLE V, where a positive IAE denotes an improvement in the temperature estimation.

$$
\triangle I A E \%=100 \cdot \frac{\operatorname{IAE}\left(2^{\text {nd }} \text { Ord }\right)-\operatorname{IAE}\left(3^{\text {rd }} \text { Ord }\right)}{\operatorname{IAE}\left(2^{\text {nd }} \text { Ord }\right)}
$$

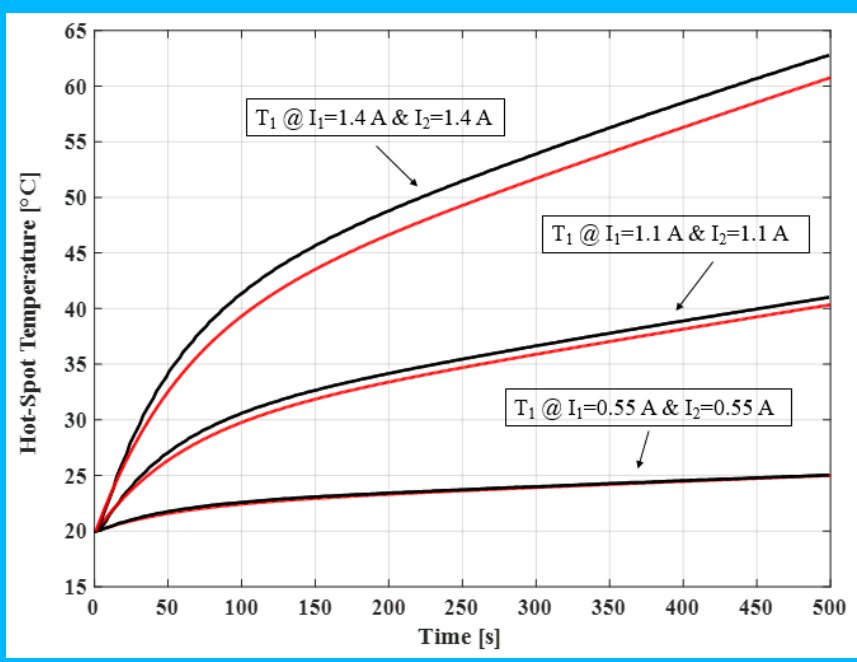

Fig. 8: Hot-spot temperature in symmetric load conditions: experimental (black) and third-order LPTN-predicted (red) profiles.

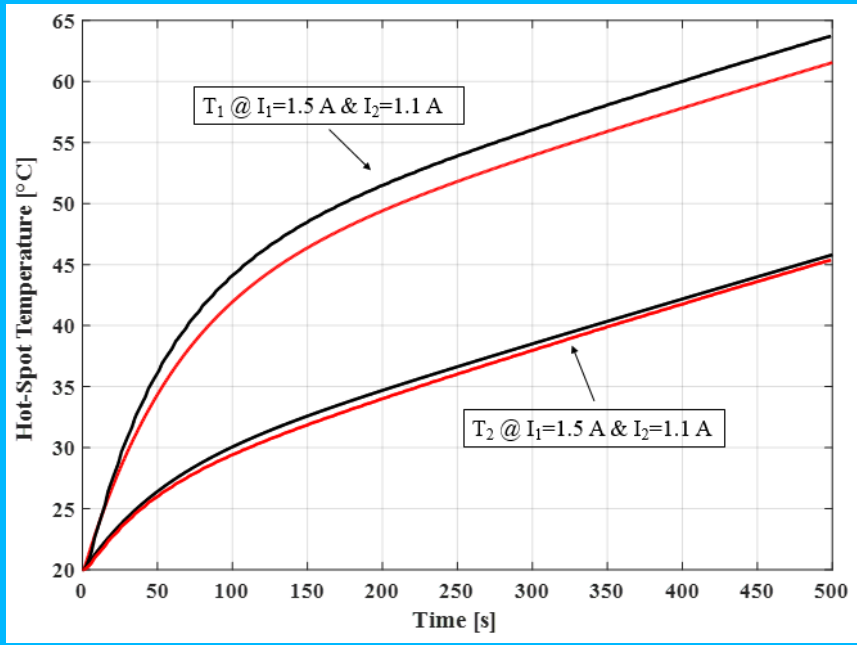

Fig. 9: Hot-spot temperature in asymmetric load conditions: experimental (black) and third-order LPTN-predicted (red) profiles.

\section{REDUCED-ORDER LPTN: CONSIDERATIONS AND APPLICATIONS}

Despite its layout simplicity, the proposed 4-nodes third-order LPTN can accurately predict the hot-spot temperature in dual three-phase PMSMs, while accounting for the thermal mutual coupling between the two winding sets. The effectiveness of the presented LPTN has been proved for both symmetric and asymmetric load conditions. In terms of computational time, the third-order LPTN takes $3.3 \mathrm{~s}$ for running a $500 \mathrm{~s}$ simulation (i.e. maximum operating time of the EMA case-study), on a personal computer equipped with an Intel ${ }^{\circledR}$ Xeon $^{\circledR}$ E5-1620 3.5 GHz CPU and 32 GB of RAM
[35]. The low computational time featured by the third-order LPTN makes this thermal tool suitable for real-time applications. In fact, the LPTN could be implemented on the electric drive's digital signal processor (DSP) for on-line temperature prediction or 'consumed' lifetime estimation. In the latter case, the LPTN is combined to an insulation lifetime model based on Miner's rule [36]. Hence, the LPTN-predicted temperature (i.e. vector temperature vs. time) is used as input for the insulation lifetime model, which provides the 'consumed' lifetime for a given duty-cycle. Further, the information regarding the 'consumed' lifetime could be stored and employed to predict the winding's time to failure according to Miner's rule [37].

TABLE IV THIRD ORDER LPTN FINE-TUNED PARAMETERS

\begin{tabular}{c|c|c|c|}
\hline \hline $\begin{array}{c}\mathbf{I}_{1} \\
{[\mathbf{A}]}\end{array}$ & $\begin{array}{c}\mathbf{I}_{\mathbf{2}} \\
{[\mathbf{A}]}\end{array}$ & $\begin{array}{c}\mathbf{T}_{\mathbf{1}} \Delta \mathbf{\Delta A E} \% \\
{[\%]}\end{array}$ & $\begin{array}{c}\mathbf{T}_{\mathbf{2}} \Delta \mathbf{\text { IAE }} \\
{[\%]}\end{array}$ \\
\hline 0.55 & 0.55 & 59.73 & 58.33 \\
\hline 1.1 & 0.55 & 86.18 & 93.26 \\
\hline 1.1 & 1.1 & 17.53 & 17.78 \\
\hline 1.5 & 0.55 & 76.09 & 73.59 \\
\hline 1.5 & 1.1 & 63.39 & 72.33 \\
\hline 1.4 & 1.4 & 37.47 & 37.12 \\
\hline 1.5 & 1.5 & 41.87 & 42.91 \\
\hline
\end{tabular}

In addition to the above applications, the third-order LPTN represents a valuable tool for electrical machine designers, since it could be adopted at the design stage of a dual three-phase PMSM for:

1. predicting the hot-spot temperature during winding fault conditions (e.g. inter-turn short-circuit, three-phase short-circuit, etc.);

2. defining the torque compensation strategy in accordance with the insulation thermal limit, for balancing the braking torque due to a three-phase short-circuit occurring in one winding set (i.e. active-shorted operating mode) [13].

In other words, if one winding set is subject to a three-phase short-circuit, then the current in the healthy winding set must be increased for compensating the braking torque and fulfil the EMA mission profile. Under this condition, the maximum temperature of the healthy winding set must be carefully controlled in order to avoid most severe failures, which might compromise the EMA mission. Finally, it is worthy to underline that at the design stage, the LPTN fine-tuning procedure should be performed on a motorette resembling the dual three-phase electrical machine.

\section{CONCLUSIONS}

In this paper, the thermal analysis of a dual three-phase PMSM designed for short-duty application was investigated. In particular, two reduced-order LPTNs were built for modeling the thermal mutual coupling between windings belonging to different phase sets. Focusing on the LPTN simplicity, a 3-nodes second-order LPTN was initially developed and experimentally fine-tuned. However, an upgrade of such LPTN was required for enhancing the temperature prediction accuracy. Therefore, a 4-nodes third-order LPTN was chosen and validated against experimental temperature profiles collected under both symmetrical and asymmetrical load conditions. The 
third-order LPTN revealed an excellent precision in estimating the transient hot-spot temperature along with a fast computation time (i.e. $\approx 3 \mathrm{~s}$ ). Several applications were briefly discussed for the presented thermal analysis tool, which range from those aiming at supporting the design of the dual three-phase PMSM (e.g. optimization and/or sensitivity analysis) to real-time implementation. Future work will consist in combining the LPTN with an insulation lifetime model for predicting the winding's life consumption due to thermal overload conditions.

\section{REFERENCES}

[1] J.C. Knight "Safety critical systems: challenges and directions," in 24th International Conference on Software Engineering. (ICSE), Orlando, FL, USA, 2002

[2] W. Cao, B.C. Mecrow, G.J. Atkinson, et al., "Overview of Electric Motor Technologies Used for More Electric Aircraft (MEA)," IEEE Transactions on Industrial Electronics, vol. 59, pp. 3523-3531, 2012.

[3] V. Madonna, P. Giangrande, C. Gerada, and M. Galea, "Thermal analysis of fault-tolerant electrical machines for aerospace actuators," IET Electric Power Applications, 2018.

[4] N. Takorabet, J.P. Caron, B. Vaseghi, B.N. Mobarakeh, F.M. Tabar and G. Humbert, "Study of Different Architectures of Fault Tolerant Actuator Using a Double-Star PM Motor," in 2008 IEEE Industry Applications Society Annual Meeting, Edmonton, Canada, 2008.

[5] S.A. Odhano, P. Giangrande, R. Bojoi, and C. Gerada, "Selfcommissioning of interior permanent magnet synchronous motor drives with high-frequency current injection," in 2013 Energy Conversion Congress and Exposition (ECCE), pp. 3852-3859, 2013.

[6] L.P. Di Noia and R. Rizzo, "Design of a five-phase permanent-magnet motor for the electric steering of an aircraft nose landing gear," in IET Electrical System in Transportation, vol. 7, pp. 327-333, 2017.

[7] A. Al-Timimy, M. Alani, M. Degano, P. Giangrande, M. Galea, and C. Gerada, "Influence of Rotor Endcaps on the Electromagnetic Performance of High Speed PM Machine," in IET Electric Power Applications, Vol. 12, no. 8, pp 1142-1149, 2018.

[8] D. Casadei, F. Filippetti, M. Mengoni, et al., "Detection of magnet demagnetization in five-phase surface-mounted permanent magnet generators," in 3rd IEEE International Symposium on Power Electronics for Distributed Generation Systems (PEDG), 2012.

[9] P. Giangrande, V. Madonna, G. Sala, A. Kladas, C. Gerada, and M Galea, "Design and Testing of PMSM for Aerospace EMA Applications," in 2018 Annual Conference of the IEEE Industrial Electronics Society - IECON 2018, Washington DC, 2018.

[10] M. Barcaro, N. Bianchi, and F. Magnussen, "Analysis and Tests of a Dual Three-Phase 12-Slot 10-Pole Permanent-Magnet Motor," IEEE Transactions on Industry Applications, vol. 46, pp. 2355-2362, 2010.

[11] P. Giangrande, A. Al-Timimy, A. Galassini, S. Papadopoulos, M. Degano and M. Galea, "Design of PMSM for EMA Employed in Secondary Flight Control Systems," in 2018 IEEE ESARS-ITEC, Nottingham UK, pp. 1-6, 2018.

[12] C. Sciascera, P. Giangrande, C. Brunson, M. Galea, and C. Gerada, "Optimal design of an electro-mechanical actuator for aerospace application" in Annual Conference of the IEEE Industrial Electronics Society (IECON), pp. 1-6, 2015.

[13] P. Giangrande, V. Madonna, S. Nuzzo, and M. Galea, "Design of FaultTolerant Dual Three-Phase Winding PMSM for Helicopter Landing Gear EMA," in ESARS-ITEC, Nottingham, UK, pp. 1-6, 2018.

[14] M. Popescu, D. A. Staton, A. Boglietti, A. Cavagnino, D. Hawkins, and J. Goss, "Modern Heat Extraction Systems for Power Traction Machines - A Review," IEEE Transactions on Industry Applications, vol. 52, pp. 2167-2175, 2016.

[15] V. Madonna, A. Walker, P. Giangrande, C. Gerada, G. Serra, and M. Galea, "Improved thermal management and analysis for stator endwindings of electrical machines," IEEE Transactions on Industrial Electronics, pp. 1-1, 2018.

[16] P. Lindh, M. G. Tehrani, T. Lindh, J. H. Montonen, J. Pyrhönen, J. T. Sopanen, et al., "Multidisciplinary Design of a Permanent-Magnet Traction Motor for a Hybrid Bus Taking the Load Cycle into Account," IEEE Trans. on Industrial Electronics, vol. 63, pp. 3397-3408, 2016.

[17] A. Boglietti, A. Cavagnino, D. Staton, M. Shanel, M. Mueller, and C. Mejuto, "Evolution and Modern Approaches for Thermal Analysis of Electrical Machines," IEEE Transactions on Industrial Electronics, vol. 56 , pp. 871-882, 2009.
[18] Z. Xu, A. Al-Timimy, M. Degano, P. Giangrande, G. Lo Calzo, H. Zhang, M. Galea, C. Gerada, S. Pickering, and L. Xia, "Thermal management of a permanent magnet motor for a directly coupled pump," in Int. Conference on Electrical Machines, pp. 1-6, 2016.

[19] V. Madonna, P. Giangrande, and M. Galea, "Electrical Power Generation in Aircraft: Review, Challenges, and Opportunities," IEEE Trans. on Transportation Electrification, vol. 4, pp. 646-659, 2018.

[20] A. Boglietti, E. Carpaneto, M. Cossale, A.L. Borlera, D. Staton and M. Popescu, "Electrical Machine First Order Short-Time Thermal Transients Model: Measurements and Parameters Evaluation," in 40th Annual Conference of the IEEE Industrial Electronics Society (IECON), Dallas, TX, USA, 2014.

[21] V. Madonna, P. Giangrande, A. Walker, and M. Galea, "On the Effects of Advanced End-Winding Cooling on the Design and Performance of Electrical Machines," in 2018 XIII International Conference on Electrical Machines (ICEM), 2018, pp. 311-317.

[22] M. Lukic, A. Hebala, P. Giangrande, C. Klumpner, S. Nuzzo, G. Chen, C. Gerada, C. Eastwick, and M. Galea "State of the Art of Electric Taxiing Systems," in 2018 ESARS-ITEC, Nottingham, UK, 2018

[23] A. Boglietti, E. Carpaneto, M. Cossale, and S. Vaschetto, "StatorWinding Thermal Models for Short-Time Thermal Transients: Definition and Validation," IEEE Transactions on Industrial Electronics, vol. 63, pp. 2713-2721, 2016.

[24] A. Boglietti, E. Carpaneto, M. Cossale, and A. L. Borlera, "Stator thermal model for short-time thermal transients," in 2014 International Conference on Electrical Machines (ICEM), 2014, pp. 1415-1421.

[25] E. Levi, R. Bojoi, F. Profumo, H. A. Toliyat, and S. Williamson, "Multiphase induction motor drives - a technology status review," IET Electric Power Applications, vol. 1, pp. 489-516, 2007.

[26] A. Al-Timimy, P. Giangrande, M. Degano, M. Galea and C. Gerada, "Investigation of AC Copper and Iron Losses in High-Speed HighPower Density PMSM," in 2018 XIII International Conference on Electrical Machines (ICEM), 2018, pp. 263-269.

[27] M. Barcaro, N. Bianchi and F. Magnussen, "Faulty Operations of a PM Fractional-Slot Machine With a Dual Three-Phase Winding," IEEE Transactions on Industrial Electronics, vol. 58, pp. 3825-3832, 2011.

[28] P. Giangrande, F. Cupertino and G. Pellegrino, "Modelling of linear motor end-effects for saliency based sensorless control," in 2010 IEEE Energy Conversion Congress and Exposition, pp. 3261-3268, 2010.

[29] F. Cupertino, G. Pellegrino, P. Giangrande, L. Salvatore, "Model based design of a sensorless control scheme for permanent magnet motors using signal injection," in 2010 Energy Conversion Congress and Exposition, pp. 3139-3146, 2010.

[30] N. Velly, N. Takorabet, F.M. Tabar, P.Y. Liegeois, F. Nierlich, F.N. Leynaert and G. Humbert, "Double channel PM motor for avionic applications: impact of winding topologies," in 2009 IEEE Energy Conversion Congress and Exposition, San Jose, CA, USA, 2009.

[31] B. Vaseghi, N. Takorabet, J.P. Caron, B.N. Mobarakeh, F.M. Tabar, and G. Humbert, "Study of Different Architectures of Fault-Tolerant Actuator Using a Two-Channel PM Motor," in IEEE Transactions on Industry Applications, Vol. 47, No. 1, pp., 47-53, January 2011.

[32] Z. Huang, T. Yang, P. Giangrande, S. Chowdhury, M. Galea, and P. Wheeler, "An active modulation scheme to boost voltage utilization of the dual converter with a floating bridge," IEEE Transactions on Industrial Electronics, vol. 66, no. 7, pp. 5623-5633, 2019.

[33] C. Gerada, M. Galea, and A. Kladas, "Electrical machines for aerospace applications," in 2015 IEEE Workshop on Electrical Machines Design, Control and Diagnosis (WEMDCD), 2015, pp. 79-84.

[34] P. Giangrande, A. Galassini, S. Papadopoulos, A. Al-Timimy, G. Lo Calzo, M. Degano, C. Gerada and M Galea, "Considerations on the development of an electric drive for a secondary flight control electromechanical actuator," in press on IEEE Transactions on Industry Applications, DOI 10.1109/TIA.2019.2907231, pp. 1-1, 2019.

[35] A. Al-Timimy, P. Giangrande, M. Degano, M. Galea and C. Gerada, "Comparative study of permanent magnet-synchronous and permanent magnet-flux switching machines for high torque to inertia applications," in 2017 IEEE Workshop on Electrical Machines Design Control and Diagnosis, pp 45-51, Nottingham, UK, April 2017.

[36] V. Madonna, P. Giangrande, L. Lusuardi, A. Cavallini, and M. Galea, "Impact of thermal overload on the insulation aging in short duty cycle motors for aerospace," in 2018 IEEE ESARS-ITEC, Nottingham UK, pp. 1-6, 2018.

[37] P. Giangrande, S. V. Bozhko, C. I. Hill and C. Gerada, "A Novel MultiLevel Electro-Mechanical Actuator Virtual Testing and Analysis Tool," in 7th IET International Conference on Power Electronics, Machines and Drives (PEMD 2014), 2014 